\title{
Burmese grape, common lime, pomelo, salak, Southern langsat, star fruit, and orange modulate the expression of cytochrome P450 enzymes in mouse livers
}

\author{
Kanokwan Jarukamjorn ${ }^{1}$ and Waranya Chatuphonprasert ${ }^{1,2 *}$ \\ ${ }^{1}$ Research Group for Pharmaceutical Activities of Natural Products using Pharmaceutical Biotechnology (PANPB), Faculty of Pharmaceutical Sciences, National \\ Research University-Khon Kaen University, Khon Kaen 40002 Thailand \\ ${ }^{2}$ Faculty of Medicine, Mahasarakham University, Mahasarakham 44000, Thailand
}

\begin{abstract}
Cytochrome P450 isoenzymes (CYPs) is responsible for xenobiotic and drug metabolism, and highly expressed in liver. Diet and daily dietary supplements might modify the expression of CYPs, leading to the undesirable side-effects of drugs. The effects of eight Thai sour fruits, namely Burmese grape (Baccaurea ramiflora Lour.), common lime (Citrus aurantifolia Linn.), pomelo (Citrus maxima (Burm) Merrill), salak (Salacca zalacca (Gaertn.) Voss), Southern langsat (Lansium domesticum Corr.), special honey orange (Lonicera japonica Thunb.), star fruit (Averrhoa carambola Linn.), and Thanathon orange (Citrus sinensis Osb.), on the expression of hepatic CYPs were determined. Effects of the aqueous extract of all fruits $(0.8$ to $25 \mathrm{mg} / \mathrm{mL})$ on the CYPs enzyme activities were determined in vitro using the reactions established enzymatic assays (EROD, MROD, BROD/PROD, and ENDM). The fruit, which possessed the most potent inhibitory activity, was selected to determine its effect in vivo on the expression and activities of CYPs in mouse livers. All eight Thai sour fruits were found to inhibit the activities of Cyp1a1, Cyp1a2, Cyp2b9/10, and Cyp3a via inhibition of EROD $\left(\mathrm{IC}_{50}=0.001-25.91 \mathrm{mg} / \mathrm{mL}\right), \mathrm{MROD}\left(\mathrm{IC}_{50}=0.681-84.95 \mathrm{mg} / \mathrm{mL}\right), \mathrm{BROD}\left(\mathrm{IC}_{50}=0.221-52.28 \mathrm{mg} /\right.$ $\mathrm{mL})$, PROD $\left(\mathrm{IC}_{50}=0.111-64.51 \mathrm{mg} / \mathrm{mL}\right)$, and ENDM $\left(\mathrm{IC}_{50}=34.27-59.62 \mathrm{mg} / \mathrm{mL}\right)$ reactions, respectively. Burmese grape exhibited the most potent inhibitory activity and inhibited the largest number of CYPs. Burmese grape was therefore selected for further in vivo study, the fruit juice being tested at a dose of 250,500 , and $1,000 \mathrm{mg} / \mathrm{kg} / \mathrm{day}$ for 7 and 28 days. The highest dose of Burmese grape (1,000 mg/kg/day) induced Cyp1a1, Cyp1a2, and Cyp2b9/10 activities. However, Cyp3a11 activity was significantly inhibited by Burmese grape treatments. Hence, Thai sour fruit consumption, especially Burmese grape, may induce food-drug interactions, particularly if they are consumed for a long time and in large quantities.
\end{abstract}

\section{Introduction}

Fruit and vegetables play a valuable role in the human diet. For example, their antioxidant activity protects against cellular damage caused by exogenous free radicals and toxicants [1]. They also aid digestion and the laxative process [2]. Thai sour fruits are popular because of their unique taste and health benefits. Several Thai sour fruits possess pharmacological activities. Sour orange (Citrus aurantium) extract has radical and superoxide scavenging activities [3], Burmese grape (Baccaurea ramiflora) extract has cytotoxic activity [4], and salak or snake fruit (Salacca zalacca) has xanthine oxidase inhibitory and antioxidant activities $[5,6]$. In addition, star fruit and lime juice inhibit CYP3A4 activity [7,8]. Food-drug interactions occur when food interferes with or changes the oral absorption of a drug, resulting in ineffectiveness or undesirable toxicities, particularly in drugs with narrow therapeutic ranges [9]. Oral bioavailability depends on several factors, including the rate and extent of drug metabolism. Cytochrome P450s (CYPs) comprise a large and diverse group of heme-thiolate isoenzymes that catalyze monooxygenase reactions in phase I metabolism. CYP activities include the conversion of drugs, xenobiotics, and other endogenous compounds into more hydrophilic compounds that are excreted in the urine or feces [10]. Alteration of the regulation of hepatic CYP activities is a key index for monitoring the toxicity of various xenobiotics and toxicants [11]. Several studies have demonstrated food-drug interactions due to CYP modification, for example the increase and decrease of felodipine bioavailability by grapefruit (Citrus paradisi) juice and orange (Citrus sinensis) juice, respectively [8]. The inhibitory effects of star fruit (Averrhoa carambola) on human CYP3A activity [7] and pomegranate (Punica granatum) on human CYP3A-mediated metabolism of carbamazepine have also been reported [12].

Currently, limited information is available on the effects of Thai fruits, especially sour tasting fruits, on the expression of CYPs. Therefore, this study investigated the effect of eight Thai sour fruits on the activities of CYPs (Cyp1a1, Cyp1a2, Cyp2b9/10, Cyp3a11) in mouse livers.

\section{Materials and methods}

\section{Chemicals}

Folin-Ciocalteu reagent, quercetin, gallic aid, resorufin, ethoxyresorufin, methoxyresorufin, benzyloxyresorufin, pentoxyresorufin,

${ }^{*}$ Correspondence to: Waranya Chatuphonprasert, Faculty of Medicine, Mahasarakham University, Mahasarakham, Thailand, Tel: +66-43-722-393; E-mail: waranya.c@msu.ac.th

Key words: food-drug interaction, Cyp1a, Cyp2b, Cyp3a, Thai sour fruit, cytochrome $P 450$

Received: June 05, 2020; Accepted: June 30, 2020; Published: July 03, 2020 

in mouse livers

erythromycin, NADPH, $p$-aminophenol and the CYPs inducers including $\beta$-naphthoflavone (BNF), phenobarbital (PB), dexamethasone (Dex) was purchased from Sigma Chemicals (St. Louis, MO). Mouse monoclonal antibodies against Cyp1a1/2, Cyp2b9/10, Cyp3a11 and peroxidase-labelled species-specific IgG were from Santa Cruz Biotechnology (Santa Cruz, CA). All other laboratory chemicals were of the highest available purity from commercial suppliers.

\section{Preparation of the fruit samples}

Eight Thai sour fruits (Tables 1 and 2), including common lime (TF-2012-CA001), pomelo (TF-2012-CM001), Thanathon orange (TF2011-CS001), special honey orange (TF-2011-LJ001), Southern langsat (TF-2011-LD001), Burmese grape (TF-2011-BR001), star fruit (TF2011-AC001), and salak (TF-2012-SZ001), were obtained from local vegetable markets in the city of Khon Kaen, Thailand during November 2012 to April 2013. All fruit samples were inspected and classified by the botanist, Dr. Pornpimon Wongsuwan, Department of Applied Thai Traditional Medicine, Faculty of Medicine, Mahasarakham University, according to botanical and morphological characteristic of the plants. The fruits were washed to clean the shell surface by soaking in Vegetable and Fruit Washing Liquid, St. Andrews (Bangkok, Thailand), which contains sodium lauryl ether sulfate $(1: 800)$ for $10 \mathrm{~min}$ as recommended by the supplier to remove dirt and pesticide residues. The fruits were then rinsed five times with distilled water, weighed, and peeled to expose the edible portion. The flesh was minced, and the juice was squeezed out and the total volume of the juice was determined. The juice was lyophilized in a freeze-dryer, and the dry powder was weight and stored at $-20^{\circ} \mathrm{C}$ until experiments. For the experiments, the powder was suspended in distilled water to give a concentration ranging from 7.81 to $250 \mathrm{mg} / \mathrm{mL}$. After centrifugation to remove undissolved particles, supernatants were collected for determination of the content of total flavonoids and phenols $(\mathrm{g} / \mathrm{mL}$ extract) and CYPs activities.

\section{Determination of total flavonoid content}

The aluminum chloride colorimetric method was applied with some modifications [13]. Briefly, the reaction mixture contained $10 \%$ aluminum chloride, $1 \mathrm{M}$ sodium acetate, and an aliquot of the fruit suspension supernatant in a final volume of $200 \mu$ l. After incubation at room temperature for $30 \mathrm{~min}$, the absorbance of the reaction mixture was measured at a wavelength of $405 \mathrm{~nm}$. Quercetin (QE) was taken as standard for calculating the content of total flavonoids. Total flavonoid content is expressed in $\mathrm{mg}$ per $\mathrm{g}$ dry weight of the standard QE.

\section{Determination of the content of total phenols}

The phenol content of the fruit samples was determined using the Folin-Ciocalteu method [13]. The supernatant of the fruit suspension was thoroughly mixed with the Folin-Ciocalteu reagent at a ratio of 1:10. After incubation for $3 \mathrm{~min}, 20 \%(\mathrm{w} / \mathrm{v}) \mathrm{Na}_{2} \mathrm{CO}_{3}$ was added. The mixture was gently mixed and allowed to stand for $30 \mathrm{~min}$ before being subjected to spectrophotometry at a wavelength of $750 \mathrm{~nm}$. Total phenolic content was calculated as the weight unit equivalent to the dry weight of the standard gallic acid (GAE) [14].

\section{Animals and treatments}

Male ICR mice at 7 weeks of age were supplied by the National Laboratory Animal Center, Mahidol University, Nakhon Pathom, Thailand and housed in the Northeast Laboratory Animal Center, Khon Kaen University, Khon Kaen, Thailand, under the supervision of a certified laboratory veterinarian. The mice were treated according to the research protocol approved by the Animal Ethics Committee for

Table 1. $\mathrm{IC}_{50}$ values of the eight Thai sour fruit juices on cytochrome P450 enzymes activities

\begin{tabular}{|c|c|c|c|c|c|}
\hline \multirow[b]{2}{*}{ Fruits } & \multicolumn{5}{|c|}{$\mathrm{IC}_{50} \mathrm{a}(\mathrm{mg} / \mathrm{mL})$} \\
\hline & $\begin{array}{l}\text { EROD }^{\mathrm{b}} \\
\text { (CYP1A1) }^{-14}\end{array}$ & $\begin{array}{l}\text { MROD }^{\mathrm{b}} \\
\text { (CYP1A2) }^{-1}\end{array}$ & $\begin{array}{c}\text { BROD }^{\mathrm{b}} \\
\text { (CYP2B9/10) }^{\text {(CYP }}\end{array}$ & $\begin{array}{c}\text { PROD }^{\mathrm{b}} \\
\text { (CYP2B9/10) }^{\text {(CYP }}\end{array}$ & $\begin{array}{c}\text { ENDM }^{\mathrm{b}} \\
\text { (CYP3A11) }\end{array}$ \\
\hline Positive control $^{\mathrm{c}}$ & $<0.001(\mathrm{BNF})$ & $0.23 \pm 0.02(\mathrm{BNF})$ & $0.023 \pm 0.002(\mathrm{~PB})$ & $<0.001(\mathrm{~PB})$ & $0.384 \pm 0.093(\mathrm{DEX})$ \\
\hline Burmese grape & $<0.01$ & $0.68 \pm 0.01$ & $0.22 \pm 0.10$ & $0.28 \pm 0.01$ & $34.27 \pm 0.32$ \\
\hline Common lime & $<0.01$ & $0.88 \pm 0.18$ & $1.09 \pm 0.61$ & $0.35 \pm 0.11$ & $36.12 \pm 0.43$ \\
\hline Pomelo & $10.37 \pm 0.60$ & $11.72 \pm 0.55$ & $20.22 \pm 3.01$ & $64.51 \pm 4.27$ & $54.89 \pm 0.71$ \\
\hline Salak & $4.33 \pm 0.20$ & $6.64 \pm 0.54$ & $20.90 \pm 3.04$ & $43.05 \pm 3.04$ & $48.77 \pm 0.82$ \\
\hline Southern langsat & $2.06 \pm 0.07$ & $62.93 \pm 4.14$ & $22.56 \pm 3.12$ & $1.20 \pm 0.08$ & $37.34 \pm 3.02$ \\
\hline Special honey orange & $25.91 \pm 3.26$ & $84.95 \pm 4.44$ & $52.28 \pm 3.96$ & $35.65 \pm 3.57$ & $59.62 \pm 4.09$ \\
\hline Star fruit & $<0.01$ & $0.71 \pm 0.02$ & $1.04 \pm 0.06$ & $0.11 \pm 0.02$ & $38.04 \pm 0.46$ \\
\hline Thanathon orange & $5.30 \pm 0.17$ & $48.42 \pm 3.88$ & $19.31 \pm 2.96$ & $20.78 \pm 3.03$ & $43.57 \pm 3.78$ \\
\hline
\end{tabular}

Note. ${ }^{a} \mathrm{IC}_{50}$ (median inhibitory concentration) values are expressed as the means $\pm \mathrm{SD}(\mathrm{n}=4-5)$ determinations from 2 independent experiments. ${ }^{\mathrm{b}}$ EROD, ethoxyresorufin $O$-deethylation; MROD, methoxyresorufin $O$-demethylation; BROD, benzyloxyresorufin $O$-alkylation; PROD, pentoxyresorufin $O$-alkylation; ENDM, erythromycin $N$-demethylation. ${ }^{\text {c } P o s i t i v e ~ c o n t r o l s ~}$ were established inducers for individual CYP isoenzymes; BNF, $\beta$-naphthoflavone for EROD and MROD; PB, Phenobarbital for BROD and PROD; Dex, dexamethasone for ENDM.

Table 2. Total flavonoid and total phenolic content of the eight Thai sour fruits

\begin{tabular}{|c|c|c|c|c|c|c|c|c|c|c|c|}
\hline \multirow{2}{*}{$\begin{array}{l}\text { Common name } \\
\text { Burmese grape }\end{array}$} & \multirow{2}{*}{$\begin{array}{l}\text { Scientific name } \\
\text { Baccaurea ramiflora } \\
\end{array}$} & \multirow{2}{*}{\begin{tabular}{|l|} 
Family \\
Phyllanthaceae \\
\end{tabular}} & \multirow{2}{*}{$\begin{array}{l}\begin{array}{l}\text { Volume of juice per } \mathrm{g} \\
\text { fruit meat }(\mathrm{mL} / \mathrm{g})\end{array} \\
0.150\end{array}$} & \multirow{2}{*}{\begin{tabular}{|l}
$\begin{array}{l}\text { Dry powder fruit } \\
\text { juice }(\mathrm{g} / \mathbf{m L})\end{array}$ \\
0.094 \\
\end{tabular}} & \multirow{2}{*}{$\begin{array}{l}\begin{array}{l}\text { Dry powder/ fruit } \\
\text { meat (mg/g) }\end{array} \\
14.10 \\
\end{array}$} & \multicolumn{3}{|c|}{$\begin{array}{l}\text { Total flavonoids }{ }^{\mathbf{a}} \text { (mg } \\
\text { QE/g dry weight) }\end{array}$} & \multicolumn{3}{|c|}{$\begin{array}{l}\text { Total phenolic }{ }^{\mathrm{b}}(\mathrm{mg} \\
\text { GAE/g dry weight) }\end{array}$} \\
\hline & & & & & & 0.039 & \pm & 0.002 & 0.166 & \pm & 0.011 \\
\hline Common lime & Citrus aurantifolia & Rutaceae & 0.348 & 0.069 & 24.01 & 0.377 & \pm & 0.060 & 0.466 & \pm & 0.017 \\
\hline Pomelo & Citrus maxima & Rutaceae & 0.279 & 0.103 & 28.74 & 0.090 & \pm & 0.028 & 0.407 & \pm & 0.010 \\
\hline Salak & Salacca zalacca & Arecacae & 0.101 & 0.162 & 16.36 & 0.042 & \pm & 0.003 & 0.135 & \pm & 0.031 \\
\hline Southern langsat & Lansium domesticum & Meliaceae & 0.248 & 0.093 & 23.06 & 0.067 & \pm & 0.003 & 0.245 & \pm & 0.028 \\
\hline Special honey orange & Lonicera japonica & Caprifoliaceae & 0.356 & 0.087 & 30.97 & 0.253 & \pm & 0.020 & 0.229 & \pm & 0.019 \\
\hline Star fruit & Averrhoa carambola & Oxalidaceae & 0.688 & 0.040 & 27.52 & 0.966 & \pm & 0.048 & 0.400 & \pm & 0.028 \\
\hline Thanathon orange & Citrus sinensis & Rutaceae & 0.300 & 0.082 & 24.61 & 0.222 & \pm & 0.018 & 0.217 & \pm & 0.042 \\
\hline
\end{tabular}

${ }^{a}$ Values are expressed as the means $\pm \mathrm{SD}(\mathrm{n}=6-9)$ from 3 independent experiments; milligrams equivalent with a gram-dry weight of quercetin $(\mathrm{QE})$. ${ }^{\mathrm{b}} \mathrm{Values}$ are expressed as the means \pm $\mathrm{SD}(\mathrm{n}=6-9)$ from 3 independent experiments; milligrams equivalent with a gram-dry weight of gallic acid (GAE). 
Jarukamjorn K (2020) Burmese grape, common lime, pomelo, salak, Southern langsat, star fruit, and orange modulate the expression of cytochrome P450 enzymes in mouse livers

Use and Care of Khon Kaen University, Khon Kaen, Thailand (Approval No. AEKKU 94/2555). All mice were housed in the University animal house in polysulfone cages containing on wood chips under a 12 -h dark/light cycle under controlled temperature $\left(23 \pm 2^{\circ} \mathrm{C}\right)$ and humidity $(45 \pm 2 \%)$. Mice received water and standard laboratory animal diet ad libitum. Before the experiments, animals were allowed to adjust to housing conditions for at least 7 days.

Mice were intraperitoneally injected with $\beta$-naphthoflavone (BNF) (30 mg/kg/day) for Cyp1a1 and Cyp1a2 induction, or phenobarbital (PB) $(100 \mathrm{mg} / \mathrm{kg} / \mathrm{day})$ for Cyp2b9/10 induction, or dexamethasone (Dex) $(30 \mathrm{mg} / \mathrm{kg} /$ day) for Cyp3a induction. All chemicals were dissolved in in corn oil for 3 consecutive days. At $24 \mathrm{~h}$ after the last treatment, the mice were sacrificed, and the livers were immediately excised and used for the preparation of microsomes for in vitro study [15].

In vivo, 250,500 , and $1000 \mathrm{mg} / \mathrm{kg} / \mathrm{day}$ in distilled water of Burmese grape juice was administered intragastrically for 7 or 28 days $(n=5)$. The control mice received the same amount of the solvent. Mice were sacrificed $24 \mathrm{~h}$ after the last treatment, and their livers were immediately excised and used for the preparation of hepatic microsomes [15].

\section{Preparation of hepatic microsomes}

The microsomal fraction was prepared by centrifugation of the liver homogenate in $1.15 \%(\mathrm{w} / \mathrm{v})$ potassium chloride at $10,000 \times \mathrm{g}$ for $10 \mathrm{~min}$ at $4^{\circ} \mathrm{C}$, and then the supernatant was subjected to ultracentrifugation at $104,000 \times g$ for $60 \mathrm{~min}$ at $4^{\circ} \mathrm{C}$ [15]. The concentration of the microsomal protein was determined with the Bradford reagent using bovine serum albumin as a standard.

\section{Assessment of Cyp activities}

The assessment of ethoxy- (EROD) for Cypla1, benzyloxy- (BROD) for Cyp2b9/10, pentoxy- (PROD) for Cyp2b9/10, and methoxy(MROD) resorufin $O$-dealkylations for Cyp1a2 were performed by the method of Sakuma et al. (1999) with modifications [16]. Briefly, a reaction mixture containing an aliquot of the fruit suspension supernatant (concentration ranging from 0.8 to $25 \mathrm{mg} / \mathrm{mL}$ ), $3 \mathrm{mM}$ Tris- $\mathrm{HCl}$ ( $\mathrm{pH}$ 7.8), $50 \mu \mathrm{M}$ NADPH, $5 \mu \mathrm{g}$ of hepatic microsomes, and $0.625 \mu \mathrm{M}$ ethoxyresorufin, benzyloxyresorufin, pentoxyresorufin, or methoxyresorufin in a final volume of $200 \mu \mathrm{l}$ was incubated at $37^{\circ} \mathrm{C}$. Subsequently, the formation of resorufin was analyzed by spectrofluorometry at an excitation wavelength of $520 \mathrm{~nm}$ and an emission wavelength of $590 \mathrm{~nm}$. Resorufin was used as a standard. The median inhibitory concentration $\left(\mathrm{IC}_{50}\right.$ ) of each fruit juice sample was calculated from the Probit analysis of extracts in the concentration range of 3.75-37.5 or 0.0625-4.8 mg/mL (IBM SPSS statistics version 23 software, Armonk, NY).

\section{Assessment of erythromycin $\mathbf{N}$-demethylase activity}

Erythromycin $N$-demethylase (ENDM) activity reflecting the activity of Cyp3a enzymes was determined via the level of formaldehyde formed in the Hantzsch reaction [17] with some modifications. Briefly, a reaction mixture consisted of an aliquot of the fruit suspension supernatant (concentration ranging from 1.6 to $50 \mathrm{mg} / \mathrm{mL}$ ), $1 \mathrm{mM}$ $\mathrm{NADPH}, 15 \mathrm{mM} \mathrm{MgC1}$, $1 \mathrm{mM}$ erythromycin, $70 \mathrm{mM}$ phosphate buffer ( $\mathrm{pH}$ 7.4), and $15 \mu \mathrm{g}$ of microsomal protein in a total volume of $100 \mu \mathrm{L}$. The reaction was initiated with the addition of NADPH and incubation for $20 \mathrm{~min}$ at $37^{\circ} \mathrm{C}$ before termination with $12.5 \%$ trichloroacetic acid. The mixture was centrifuged at 1,900 rpm for $15 \mathrm{~min}$. An aliquot of the supernatant was added to the Nash reagent and incubated at $60^{\circ} \mathrm{C}$ for $15 \mathrm{~min}$ before measuring the absorbance at a wavelength of $405 \mathrm{~nm}$, and was compared to the formaldehyde standard $[18,19]$. The $\mathrm{IC}_{50}$ of each fruit juice sample was calculated by Probit analysis using SPSS (IBM SPSS statistics version 23 software, Armonk, NY).

\section{Western blot analysis of Cyp proteins control house-keeping enzyme}

The expression of Cyp proteins was determined by Western blot analysis as described previously [20]. Briefly, five to twenty micrograms of the microsomal proteins were seperated by $10 \%$ sodium dodecyl sulfate-polyacrylamide gel electrophoresis (SDS-PAGE) and then transferred to a Hybond-C membrane. Membranes were blocked overnight at $4^{\circ} \mathrm{C}$ in phosphate buffered saline (PBS) containing $0.03 \%$ tween-20 and $1 \%$ bovine serum albumin. The Cyp proteins were detected using a rabbit or goat polyclonal antibody against mouse Cyp1a/2, Cyp1b1, Cyp2b9/10, or Cyp3a11. The membranes were incubated with rabbit anti-goat-IgG-HRP or biotinylated goat anti-rabbit IgGHRP. Finally, the antigen-antibody complexes were visualized with 3, 3'-diaminobenzidine (DAB) agent and hydrogen peroxide. The specific Cyp bands were quantified densitometrically and the Cyp content is expressed in arbitrary units corresponding to the signal intensity.

\section{Statistical analyses}

The results were expressed as the means \pm SD for each group. Data were analyzed by one-way analysis of variance (ANOVA) followed by Tukey post hoc test (IBM SPSS statistics version 23 software, Armonk, NY). Differences with a $p<0.05$ were considered statistically significant.

\section{Results}

Inhibitory effect of the eight Thai sour fruits on hepatic cytochrome $\mathbf{P} 450$ activities in mouse microsomes

The inhibitory activity of the eight test fruits on the hepatic CYP enzymes Cyp1a1, Cyp1a2, Cyp2b9/10, and Cyp3a11 was determined in vitro using mouse microsomes. Enzymatic activities tested included EROD, MROD, BROD/PROD [16], and ENDM [17]. Each fruit powder was dissolved in distilled water at concentrations ranging from 3.7537.5 or $0.0625-4.8 \mathrm{mg} / \mathrm{mL}$. Compared to the control, which contained no fruit samples and represented 100\% Cyp activity, all fruit juices showed inhibitory activity in nearly every enzyme reaction (Table 1). Although none of the fruits inhibited the reactions with the potency of the typical substrates (BNF, PB, and Dex), a trend in the alteration of the enzyme activities was observed. Sequentially, the $\mathrm{IC}_{50}$ values for inhibition of EROD activity were Burmese grape $<$ star fruit $<$ common lime $<$ Southern langsat $<$ salak $<$ Thanathon orange $<$ special honey orange. Moreover, Burmese grape juice showed the lowest $\mathrm{IC}_{50}$ value in several enzymatic reactions including MROD, BROD, and ENDM, while special honey orange had the highest $\mathrm{IC}_{50}$ concentration in those reactions. It was only for PROD activity that star fruit showed a lower $\mathrm{IC}_{50}$ than Burmese grape. Therefore, Burmese grape juice was selected for further in vivo study. Burmese grape juice was given to the mice at doses of 250,500 , and $1,000 \mathrm{mg} / \mathrm{kg} /$ day for short and long periods (7 and 28 days). Mouse liver microsomes were isolated and used to determine the expression of Cyp enzymes.

\section{Content of total flavonoid and phenols in the eight Thai fruits}

Using the standard curve of quercetin (QE) for total flavonoid content, the highest flavonoid content was found in the star fruit $(0.966$ $\mathrm{mg} \mathrm{QE} / \mathrm{g}$ ), followed by common lime, special honey orange, Thanathon orange, pomelo, Southern langsat, salak, and Burmese grape (Table 2). The total phenolic content based on the amount of gallic acid (GAE) 

in mouse livers

in the eight Thai sour fruits varied from 0.135 to $0.466 \mathrm{mg}$ GAE/g. The common lime had the highest total phenolic content $(0.466 \mathrm{mg} \mathrm{GAE} / \mathrm{g})$, followed by pomelo, star fruit, Southern langsat, special honey orange, Thanathon orange, Burmese grape, and salak (0.135 mg GAE/g).

\section{Effects of Burmese grape on Cyp enzyme activities in mouse} livers

The mice were given Burmese grape extract intragastrically at 250, 500 , and $1,000 \mathrm{mg} / \mathrm{kg} /$ day for 7 or 28 consecutive days. The impact of the Burmese juice on hepatic cyp activities including Cyp1a1, Cyp1a2, Cyp2b9/10, and Cyp3a11 enzymes, was determined in comparison to established Cyp inducers BNF (for Cyp1a1 and Cyp1a2), PB (for Cyp2b9/10), and Dex (for Cyp3a11). Significant increases in EROD, MROD, BROD, and PROD activities were observed (Figure 1A and $2 \mathrm{~A}$ ) in a time- and dose-dependent pattern by Burmese grape juice compared with those of the non-treament group (NT). ENDM activity, by contrast, was inhibited (Figure 3A).

\section{Effect of Burmese grape on expression of Cyp proteins}

To investigate whether Burmese grape influenced the expression of CYPs at the translation level, Western blot analysis was performed. The daily administration of Burmese grape juice at 500 and 1,000 mg/ $\mathrm{kg}$ /day for 7 and 28 days significantly up-regulated the expression of Cyp1a1/2 protein (Figure 1B), while Cyp2b9 and Cyp2b10 proteins were increased in the 28 day-treatment only (Figure $2 \mathrm{~B}$ ). The highest dose of Burmese grape suppressed Cyp3a11 protein expression in both the 7 days and 28 days treatments (Figure 3B). These observations show that Cyp protein expression is consistent with the activities of Cyp enzymes.

\section{Discussion}

Several studies emphasized bioactive importance of flavonoids and phenolic analogs in herbs or fruits, i.e., antioxidant activity, anticancer, etc. [21]. The inhibitory activity of the eight Thai sour fruits on CYP enzyme activities did not correlate with total phenolic and flavonoid content. The Burmese grape juice exhibited the strongest inhibitory effect (the lowest $\mathrm{IC}_{50}$ ) on cyp activities of all the test fruits, but its total phenolic and flavonoid contents were not the most abundant. Therefore, besides the phenolic and flavonoid content, other constituents of the Burmese grape might be influencing cyp activities.

CYP1A1 and CYP1A2 activities are generally measured as the rate of $O$-dealkylation of 7-ethoxyresorufin (ER) and 7-methoxyresorufin (MR) for EROD and MROD reactions [22]. CYP1A1 is involved in carcinogenesis [23], while CYP1A2 is involved in the metabolism of $\mathrm{N}$-heterocyclics amine and arylamines. Emerging technology from knockout mice has demonstrated that hepatic CYP1A1 and CYP1A2 are very important in detoxication of the liver [24]. Furthermore, extensive research has reported that CYP1A1 and CYP1A2 are regulated via the aryl hydrocarbon receptor (AhR) [23]. Several herbal plant, vegetable and fruit extracts have been shown to activate or suppress AhR expression because of their flavonoid and phenolic constituents $[24,25]$. Cyp2b9 and Cyp2b10 are major Cyp2b isoenzymes in mice, expressed both constitutively and inducibly [15]. The classical inducers phenobarbital $(\mathrm{PB})$ and the synthetic glucocorticoid dexamethasone (Dex) modulate cyp2b expression in mouse liver [26,27]. In this study, PB significantly increased the activities of BROD, PROD, and Cyp2b9/10 protein in mouse livers. This correlates well with the findings of Jarukamjorn et al. [27], that Alteration of cyp2b activities might

A) EROD \& MROD

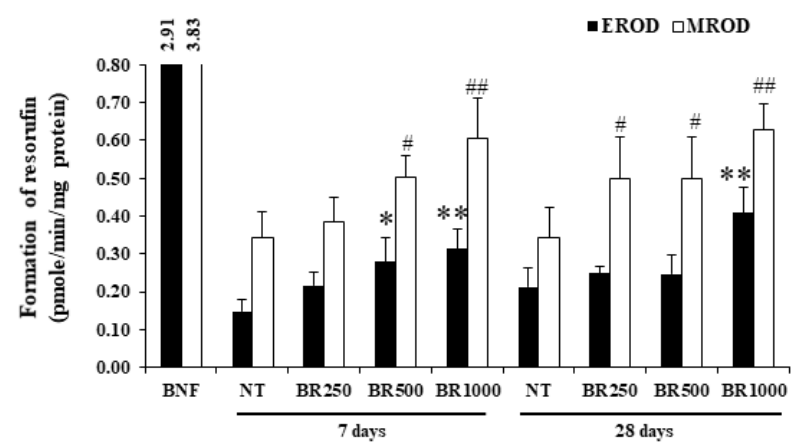

B) CYPlAl/2 Protein; $10 \mu \mathrm{g}$ hepatic microsome

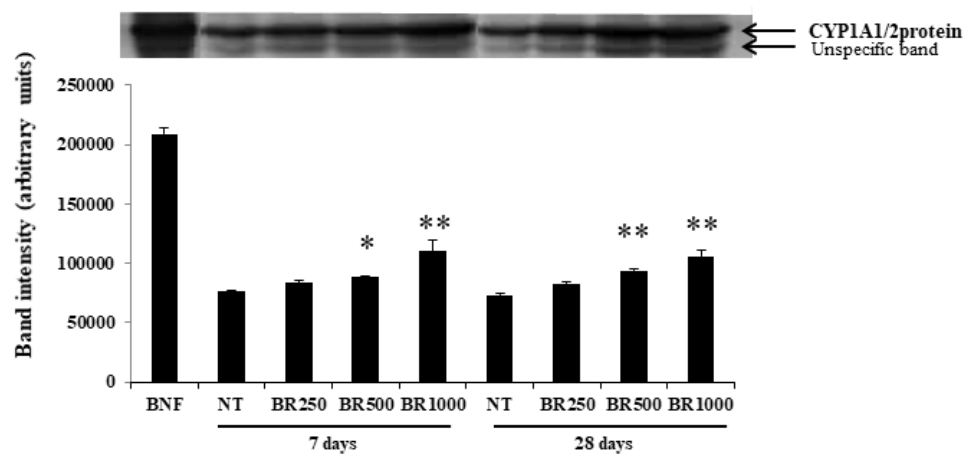

Figure 1. Modifications of hepatic Cyp1a1, Cyp1a2 activities and Cyp1a1/2 protein by Burmese grape. In the treatment group, 250, 500, and 1,000 mg/kg Burmese grape (Baccaurea ramiflora, BR) was given intragastrically every day for 7 or 28 days $(\mathrm{n}=5$ mice). The non-treatment (NT) group received distilled water intragastrically in parallel. Mice in the positive group were treated with $\beta$-naphthoflavone (BNF) intraperitoneally at a dose of $30 \mathrm{mg} / \mathrm{kg} /$ day for 3 consecutive days. The results were expressed as means $\pm \mathrm{SD}(\mathrm{n}=5)$. $*$ and $* *$ represent significantly different results (treatment vs NT group) at $p<0.05$ and $p<0.001$, respectively for EROD activity. ${ }^{\#}$ and ${ }^{\#}$ represent significantly different results (treatment vs NT group) at $p<0.05$ and $p<0.001$, respectively for MROD activity (one-way ANOVA, followed by Tukey post hoc test). 


\section{A) BROD \& PROD}

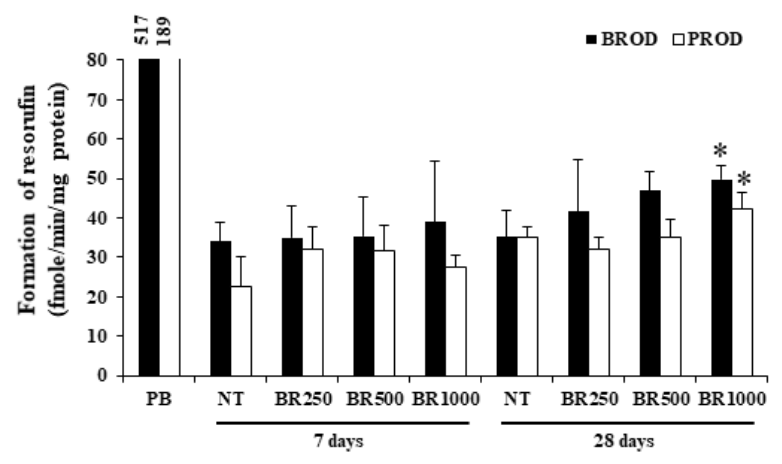

B) CYP2B9/10 Protein; $10 \mu \mathrm{g}$ hepatic microsome
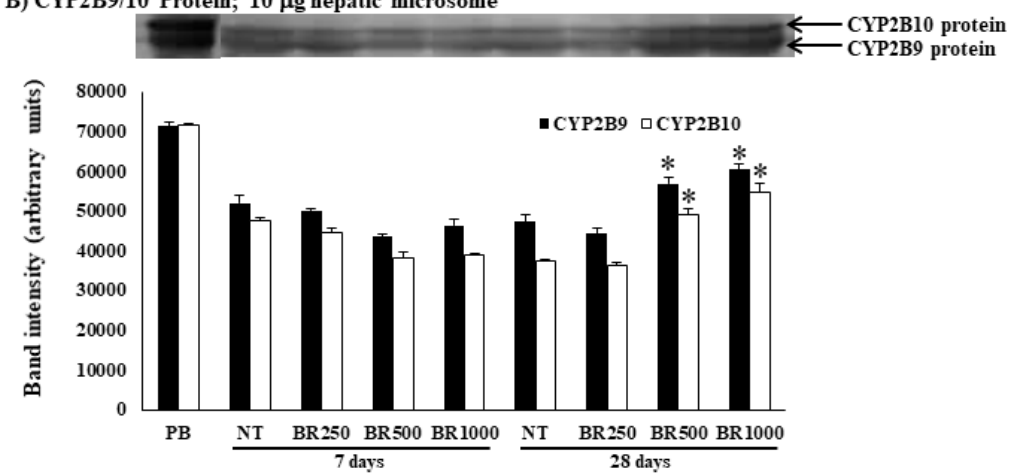

Figure 2. Modifications of hepatic Cyp2b9, Cyp2b10 and Cyp b9/10 protein by Burmese grape. The mice were administered with 250,500 , and 1,000 mg/kg Burmese grape (BR) intragastrically every day for 7 or 28 days (treatment group; $n=5$ ). To the non-treatment (NT) group, distilled water was given intragastrically in parallel. The positive control group received phenobarbital (PB) intraperitoneally at a dose of $100 \mathrm{mg} / \mathrm{kg} /$ day for 3 consecutive days. The results were expressed as means $\pm \mathrm{SD}(\mathrm{n}=5$ ).

*represents significantly different results (treatment vs NT group at $p<0.05$ (one-way ANOVA, followed by Tukey post hoc test).

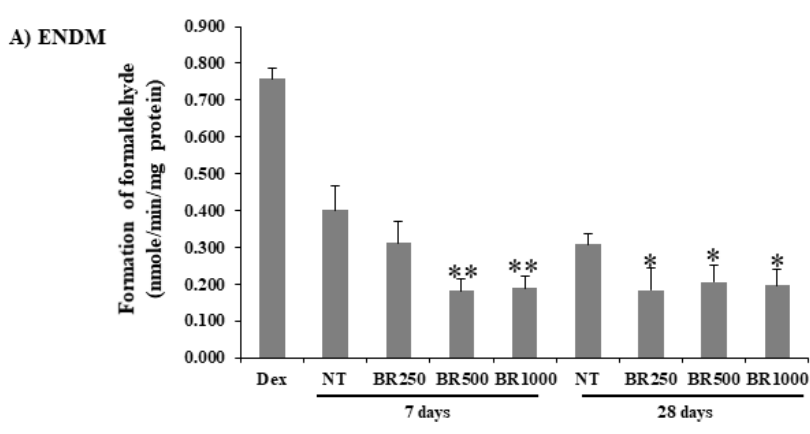

B) CYP3All Protein; $15 \mu \mathrm{g}$ hepatic microsome

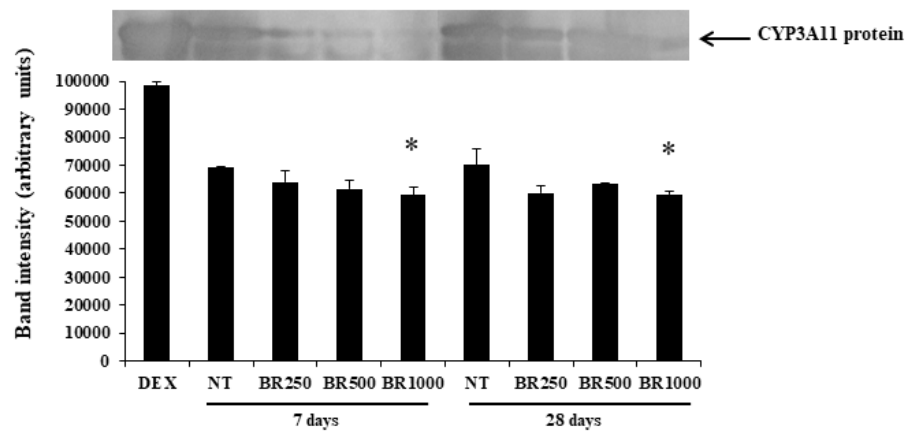

Figure 3. Modifications of hepatic Cyp3a11 activity and Cyp3a11protein by Burmese grape. The mice were administered with 250, 500, and 1,000 mg/kg Burmese grape (BR) intragastrically every day for 7 or 28 days $(n=5)$. The non-treatment $(\mathrm{NT})$ group was given distilled water intragastrically in parallel. Positive control mice were given dexamethasone (DEX) intraperitoneally at a dose of $30 \mathrm{mg} / \mathrm{kg} /$ day for 3 consecutive days. The results were expressed as means $\pm \mathrm{SD}(\mathrm{n}=5)$.

$*$ and $* *$ represent significantly different results from the NT group at $p<0.05$ and $p<0.001$, respectively (one-way ANOVA, followed by Tukey post hoc test). 
Jarukamjorn K (2020) Burmese grape, common lime, pomelo, salak, Southern langsat, star fruit, and orange modulate the expression of cytochrome P450 enzymes in mouse livers

disturb metabolism of corticosteroids and sex-hormones. Cyp3a11 is the murine homolog of human CYP3A4. CYP3A4 is the major human CYP isoform in the liver which metabolizes steroid compounds and over $40 \%$ of marketed drugs [28]. Patients with chronic disease should therefore be advised to avoid consuming large quantities of these fruits or fruit juices over a long period, as they may interfere with metabolism of prescribed medications via modification of CYP1A, CYP2B9/10, and CYP3A, leading to ineffective treatments or adverse drug reactions.

The potency of each fruit on CYP expression was determined in vitro, but induction effects cannot be determined in vitro. Therefore, an in vivo study was performed using Burmese grape which had shown the greater inhibitory potential on several CYP isoforms. No significant toxicity or abnormal symptoms were detected in the mice during the period of study (28 days). The Burmese grape elevated activities of the Cyp1a1, Cyp1a2, Cyp2b9/10 and Cyp3a11 enzymes via significant increases of EROD, MROD, BROD, and PROD, respectively, in the mouse livers in parallel to the expression levels of the Cypla1, Cypla2, and Cyp2b9/10 proteins. The daily dose of $250 \mathrm{mg} / \mathrm{kg}$ Burmese grape juice administered in the present study was equivalent to a $200 \mathrm{~mL}$ aliquot of Burmese grape juice. Daily consumption of the lowest dose of Burmese grape juice $(250 \mathrm{mg} / \mathrm{kg} / \mathrm{day})$ for up to 1 month did not significantly affect the expression of Cyp1a1 and Cyp2b9/11 in mouse liver, but Cyp1a2 was induced via MROD activity and Cyp3a11 protein was inhibited. The number of modified CYPs increased following consumption of high doses of Burmese grape juice or consumption of the juice over long periods. These findings suggest that the effects of Burmese grape on CYP isozymes merit further clinical investigation. The nutrient composition of raw Burmese grapefruit per $100 \mathrm{~g}$ edible portion conducted in Thailand was reported as moisture $88.2 \mathrm{~g}$, energy $48 \mathrm{kcal}$, protein $0.7 \mathrm{~g}$, fat $0.3 \mathrm{~g}$, carbohydrate $10.5 \mathrm{~g}$, ash $0.3 \mathrm{~g}, \mathrm{Ca} 2$ $\mathrm{mg}, \mathrm{Fe} 3.3 \mathrm{mg}$, and vitamin C $55 \mathrm{mg}$ [29]. The leaves of Burmese grape contained 6' $-O$-vanilloylisotachioside and 6'-O-vanilloyltachioside [30]. However, the information of this plant's effect on CYPs has no reports. Hence, it is interesting to determine which is the important compounds affect to CYPs for further study.

Although CYP1A1 and CYP1A2 are regulated by AhR, the mechanisms of the transcriptional regulation of these two genes are not the same [31]. There are several pathways involved in the regulation of CYP1A1 and CYP1A2 including the AhR pathway [16], the retinoid X receptor pathway [32], and activation of protein tyrosine kinase [24]. CYP2B activity is induced by corticorsteroids and sex-hormones [15]. The mechanism involved in CYP2B9/10 induction may depend on sex, duration and/or route of inducer treatment, maturation stage, and pituitary factor [15,27]. In the present study, the effect of Burmese grape on cyp $2 b$ induction might be due to the constituents, concentration, and duration of treatments. Cyp3a11 was induced by dexamethasone [33]. Induction of CYP3A expression is known to be regulated by nuclear receptors; pregnane $\mathrm{X}$ receptor (PXR) and constitutive androstane receptor (CAR) [34]. Although the constituents of Burmese grape juice have not been determined, some substances in Burmese grape might be ligands of PXR or CAR receptors.

\section{Conclusion}

Burmese grape, common lime, pomelo, Thanathon orange, special honey orange, Southern langsat, star fruit, and salak, were all found to alter Cyp isoenzymes in mouse microsomes. Cyp enzymes affected include Cyp1a1. Cyp1a2, Cyp2b9/10, and Cyp3a. This raises concerns about food-drug interactions, with the possibility of clinically ineffective drug treatments and undesirable or toxic effects. Consumption of these eight Thai sour fruits, especially Burmese grape, should therefore be avoided in patients taking medicine with a narrow therapeutic index.

\section{Acknowledgments}

This study was funded by Faculty of Medicine, Mahasarakham University and the Research Group for Pharmaceutical Activities of Natural Products using Pharmaceutical Biotechnology (PANPB), Faculty of Pharmaceutical Sciences, Khon Kaen University, Thailand. The English-editing assistance of Dr. Tim Cushnie, Mahasarakham University, is kindly acknowledged.

\section{References}

1. Dillard CJ, German JB (2000) Phytochemicals: Nutraceuticals and human health. $J$ Sci Food Agric 80: 1744-1756.

2. Weisburger JH, Reddy BS, Rose DP, Cohen LA, Kendall ME, et al. (1993) Protective mechanisms of dietary fibers in nutritional carcinogenesis. Basic Life Sci 61: 45-63. [Crossref]

3. Jayaprakasha GK, Girennavar B, Patil BS (2008) Radical scavenging activities of Rio Red grapefruits and sour orange fruit extracts in different in vitro model systems. Biores Tech 99: 4484-4494.

4. Howlader MA, Apu AS, Saha RK, Rizwan F, Nasrin N, et al. (2012) Cytotoxic activity of $n$-hexane, chloroform and carbon tetrachloride fractions of the ethanolic extract of leaves and stems of Baccaurea ramiflora (Lour.). Int J Pharm Sci Res 3: 822-825.

5. Azmi SMN, Jamal P, Amid A (2012) Xanthine oxidase inhibitory activity from potential Malaysian medicinal plant as remedies for gout. Int Food Res J 19: 59-66.

6. Aralas S, Mohamed M, Fadzelly M, Bakar A (2009) Antioxidant properties of selected salak (Salacca zalacca) varieties in Sabah, Malaysia. Nutr Food Sci 39: 243-250.

7. Hidaka M, Fujita K, Ogikubo T, Yamasaki K, Iwakiri T, et al. (2004) Potent inhibition by star fruit of human cytochrome P450 3A (CYP3A) activity. Drug Metab Dispos 32: 581-583. [Crossref]

8. Bailey DG, Dresser GK, Bend JR (2003) Bergamottin, lime juice, and red wine as inhibitors of cytochrome P450 3A4 activity: Comparison with grapefruit juice. Clin Pharmacol Ther 73: 529-537. [Crossref]

9. Dresser GK, Bailey DG (2003) The effects of fruit juices on drug disposition: A new model for drug interactions. Eur J Clin Invest 33: 10-16. [Crossref]

10. Williams PA, Cosme J, Sridhar V, Johnson EF, McRee DE (2000) The crystallographic structure of a mammalian microsomal cytochrome P450 monooxygenase: structura adaptations for membrane binding and functional diversity. Mol Cell 5: 121-132.

11. Commandeur JNM, Stijntzes GJ, Vermeulen NPE (1995) Enzyme and transport systems involved in the formation and disposition of glutathione S-conjugates: Role in bioactivation and detoxication mechanisms of xenobiotics. Pharmacol Rev 47: 217 330

12. Hidaka M, Okumura M, Fujita K, Ogikubo T, Yamasaki K, et al. (2005) Effects of pomegranate juice on human cytochrome p450 3A (CYP3A) and carbamazepine pharmacokinetics in rats. Drug Metab Dispos 33: 644-648. [Crossref]

13. Chatuphonprasert W, Jarukamjorn K (2012) Impact of six fruits-banana, guava, mangosteen, pineapple, ripe mango and ripe papaya-on murine hepatic cytochrome P450 activities. $J$ Appl Toxicol 32: 994-1001.

14. Maisuthisakul P, Suttajit M, Pongsawatmanit R (2007) Assessment of phenolic conten and free radical-scavenging capacity of some Thai indigenous plants. Food Chem 100: 1409-1418.

15. Jarukamjorn K, Sakuma T, Miyaura J, Nemoto N (1999) Different regulation of the expression of mouse hepatic cytochrome P450 CYP2B enzyme by glucocorticoid and phenobarbital. Arch Biochem Biophys 396: 89-99.

16. Sakuma T, Ohtake M, Katsurayama Y, Jarukamjorn K, Nemoto N (1999) Induction of CYP1A2 by phenobarbital in the livers of aryl hydrocarbon-responsive and -nonresponsive mice. Drug Metab Dispos 27: 379-384. [Crossref]

17. Roberts BJ, Elizabeth S, Shoaf SE, Song BJ (1995) Rapid changes in cytochrome $\mathrm{P} 4502 \mathrm{El}$ (CYP2E1) activity and other P450 isozymes following ethanol withdrawal in rats. Biochem Pharmacol 49: 1666-1673.

18. Nash T (1953) The colorimetric estimation of formaldehyde by means of the Hantzsch reaction. Biochem J 55: 416-421. [Crossref] 
19. Compton BJ, Purdy WC (1980) The mechanism of the reaction of the Nash and the Sawicki aldehyde reagent. Can J Chem 58: 2207-2211.

20. Jarukamjorn K, Kondo S, Chatuphonprasert W, Sakuma T, Kawasaki Y, et al. (2010) Gender-associated modulation of inducible CYP1A1 expression by andrographolide in mouse liver. Eur J Pharm Sci 39: 394-401. [Crossref]

21. Proteggente AR, Pannala AS, Paganga G, Buren L, Wagner E, et al. (2002) The antioxidant activity of regularly consumed fruit and vegetables reflects their phenolic and vitamin C composition. Free Radic Res 36: 217-233. [Crossref]

22. Burke MD, Thompson S, Weaver RJ, Wolf CR, Mayer RT (1994) Cytochrome P450 specificities of alkoxyresorufin $O$-dealkylation in human and rat liver. Biochem Pharmacol 48: 923-936. [Crossref]

23. Delescluse C, Lemaire G, Sousa G, Rahmani R (2000) Is CYP1A1 induction always related to AHR signaling pathway? Toxicology 153: 73-82. [Crossref]

24. Uno S, Dalton TP, Derkenne S, Curran CP, Miller ML, et al. (2004) Oral exposure to benzo $[a]$ pyrene in the mouse: detoxication by inducible cytochrome $\mathrm{P} 450$ is more important than metabolic activation. Mol Pharmacol 65: 1225-1237. [Crossref]

25. Ciolino HP, Yeh GC (1999) The flavonoid galangin is an inhibitor of CYP1A1 activity and an agonist/antagonist of the aryl hydrocarbon receptor. Br J Cancer 79: 1340-1346. [Crossref]

26. Meehan RR, Forrester LM, Stevenson K, Hastie ND, Buchmann A, et al. (1988) Regulation of phenobarbital-inducible cytochrome P-450s in rat and mouse liver following dexamethasone administration and hypophysectomy. Biochem J 254: 789797. [Crossref]
27. Jarukamjorn K, Sakuma T, Nemoto N (2002) Sexual dimorphic expression of mouse CYP2B: alterations during development or after hypophysectomy. Biochem Pharmacol 63: 2037-2041.

28. Guengerich FP (2008) Cytochrome P450 and chemical toxicology. Chem Res Toxicol 21: 70-83. [Crossref]

29. Lim TK (2012) Baccaurea ramiflora edible medicinal and non-medicinal plants. Fruits 4: $248-251$

30. Yang XW, Wang JS, Ma YL, Xiao HT, Zuo YQ, et al. (2007) Bioactive phenols from the leaves of Baccaurea ramiflora. Planta Med 733: 1415-1417. [Crossref]

31. Nemoto N, Sakurai J (1993) Activation of Cypla1 and Cypla2 genes in adult mouse hepatocytes in primary culture. Jpn J Cancer Res 84: 272-278. [Crossref]

32. Vecchini F, Lenoir-Viale MC, Cathelineau C, Magdalou J, Bernard BA, et al. (1994) Presence of a retinoid responsive element in the promoter region of the human cytochrome P4501A1 gene. Biochem Biophys Res Commun 201: 1205-1212.

33. Yanagimoto T, Itoh S, Sawada M, Hashimoto H, Kamataki T (1994) Molecular cloning and functional expression of a mouse cytochrome P-450 (Cyp3a-13): examination of Cyp3a-13 enzyme to activate aflatoxin B1 (AFB1). Biochim Biophys Acta 1201: 405410. [Crossref]

34. Down MJ, Arkle S, Mills JJ (2007) Regulation and induction of CYP3A11, CYP3A13 and CYP3A25 in C57BL/6J mouse liver. Arch Biochem Biophys 457: 105-110. [Crossref]

Copyright: (C2020 Jarukamjorn K. This is an open-access article distributed under the terms of the Creative Commons Attribution License, which permits unrestricted use, distribution, and reproduction in any medium, provided the original author and source are credited. 